\title{
Fate of nonylphenol compounds in the treatment of simulated denim
}

\author{
wastewater \\ Zijian Zhou ${ }^{1,2, a}$, Zhencheng Xu' ${ }^{1, b}$, Qingwei Guo ${ }^{1, \mathrm{c}}$, Kai Cui ${ }^{1, \mathrm{~d}}$ \\ ${ }^{1}$ South China Institute of Environmental Sciences, MEP, Guangzhou 510655, China \\ ${ }^{2}$ Environmental Science and Engineering College, Guilin University of Technology, Guilin Guangxi \\ Zhuang Nationality Autonomous Region 541004, China \\ a robterman@qq.com, ${ }^{b}$ xuzhencheng@scies.org, ${ }^{c}$ quoqingwei@scies.org, \\ 'cuikai1230@163.com,
}

Article Note: funded by the Water Pollution Control and Treatment Special Project of China (2012ZX07206-003)

Keywords: denim wastewater, nonylphenol ethoxylates, nonylphenol polyethoxy carboxylates, hydrolysis anaerobic, contact oxidation, conventional aerobic sludge.

Abstract. Two denim wastewater treatment processes are investigated for their efficiencies to remove the surfactant, nonylphenol ethoxylates (NPEOs). It is found that the acrid environment of the simulated denim wastewater shows no influence on the removal of NPEOs. After treatment through hydrolysis anaerobic tank, aerobic tank and sediment tank in sequence, the removal efficiency of total NPEOs $(6.25-12.5 \mathrm{mg} / \mathrm{L})$ in the wastewater can achieve a value of around $90 \%$. But the concentration of low molecular weight NPEOs and nonylphenol polyethoxy carboxylates (NPECs) is not as low as anticipated. The quantity of low molecular weight NPEOs (2300-7500 $\mu \mathrm{g} / \mathrm{L})$ produced in the hydrolysis anaerobic unit will not be greatly reduced in the aerobic unit and achieves a removal efficiency of around $60 \%$. Substantial quantities of low molecular weight NPEOs $(750-2100 \mu \mathrm{g} / \mathrm{L})$ remained in the outlet. A harsher environment in the conventional aerobic sludge tank will boost the production of low molecular weight NPECs (1600 $\mu \mathrm{g} / \mathrm{L}$ to $4000 \mu \mathrm{g} / \mathrm{L}$ ) because it promotes the contact among nonylphenol compounds, oxygen, and biomass. The contact oxidation unit is an appropriate unit for the reduction of NPECs $(98 \mu \mathrm{g} / \mathrm{L}$ to $850 \mu \mathrm{g} / \mathrm{L})$ in the effluent for its relatively neutral environment. The operating parameters such as inner recycle rate of anaerobic unit and the composition of simulated wastewater showed significant effect on the quantities of nonylphenol compounds reduced or produced during the treatment process. A high recycle rate will prompt the biodegradation of total NPEOs. Also, a composition with more dyes in the wastewater will increase the removal rate of total NPEOs and can become an important factor to influence the transformation of NPEOs in the anaerobic unit.

\section{Introduction.}

Nonylphenol ethoxylates (NPEOs) have been widely used in the world for their excellent surfactant properties and cheap manufacturing. Belonging to alkylphenol ethoxylates (APEOs), NPEOs quantitatively make up around $80 \%$ of the APEOs used globally every year. In USA, 13,000 tons of APEOs were used in 2006 [1]. Similarly, in 2000, the amounts of APEOs used in western Europe and Asia were 11,600 and 200,000 tons respectively [2]. In 2000, EU restricted the use of NPEOs for being awaken of their environment impact, due to which their consumption in the region has decreased drastically[3]. However, the corresponding amounts consumed in Asia have been 
increasing in recent years. It is estimated that the amount of NPEOs imported by china in 2011 was around 180,000 tons, while that of nonylphenol (NP) which is used to produce NPEOs reached around 100,000 tons [4]. Considering the annual increase rate of NPEOs estimated to be more than $8 \%$, the total amounts of NPEOs consumed in 2016 will reach 230,000 tons[5].

The environmental concerns regarding the use of NPEOs arise from the endocrine effect due to their degradation products, which include NP and low-molecular weight NPEO or nonylphenol polyethoxy carboxylate (NPEC) [6]. In 1978, a combination of endocrine and estradiol was detected due to the use of APEOs [7]. In 1991, studies revealed that the proliferation of estrogen-dependent breast cancer resulted from the presence of NPEOs [8]. Further studies showed endocrine influences of NP, octylphenol (OP), nonylphenol carboxylate (NP1EC), and nonylphenol diethoxylate (NP2EO) on the living organisms [6]. Due to these adverse environmental and health impacts, the regulatory bodies began to limit the use of NPEOs since the start of current century. EU restricted the use of NPEOs in 2003 through a directive (Directive 2003/53/EC, 2003). USA listed NPEOs in the "Restricted substances list" (the 10 $10^{\text {th }}$ edition) in 2012 and hence placed a restriction on their large scale use. However, a similar restriction has not yet taken place in China. The amounts of NPEOs and their degradation products discharged into the aquatic bodies have been large for many years and consequently, have been detected in many domestic water bodies $[9,10]$.

Industrial wastewater is one of the largest sources, contaminated heavily by NPEOs[11]. Dyeing and finishing industry is one of the industries in which NPEOs are substantially used[12]. Denim is one of the fabrics which require extensive treatment by detergent and dye additives made up of NPEOs during its final processing. This way, NPEOs find their way into the waters even after extensive treatment is applied to the wastewater.

Methods to eliminate NPEOs in laboratory and urban sewage treatment have been studied for many years. The elimination route and the biodegradation path has been one of the main research focuses in recent years. Little information is recorded on their elimination from industrial wastewater treatment plants. The present study focuses on eliminating NPEOs from the industrial wastewater originating from denim's treatment. Two different existing processes have been mimicked in the laboratory and have also been simulated with regards to the treatment of denim wastewater. Based on the results obtained, the efficiencies of the processes have been evaluated and the elimination route of NPEOs in denim wastewater treatment has been proposed. The results are aimed to make contribution to improving the efficiency of the treatment process.

\section{Experimental}

Methodology. Four simulated dyeing wastewater treatment processes were constructed in the laboratory. These were composed of a hydrolytic acidification unit, an aeration unit, and a vertical sedimentation unit (see Figure 1). Anaerobic baffled reactor (ABR) was used in hydrolytic acidification unit. Fillers were installed in upward section of the ABR for the enrichment of anaerobic biomass. Processes 1 and 2 were classified under group 1 for their similar contact aeration tank installed with fillers. Process 3 and 4 were classified as group 2 for their same conventional active sludge aeration tanks adopted in the aeration unit. 


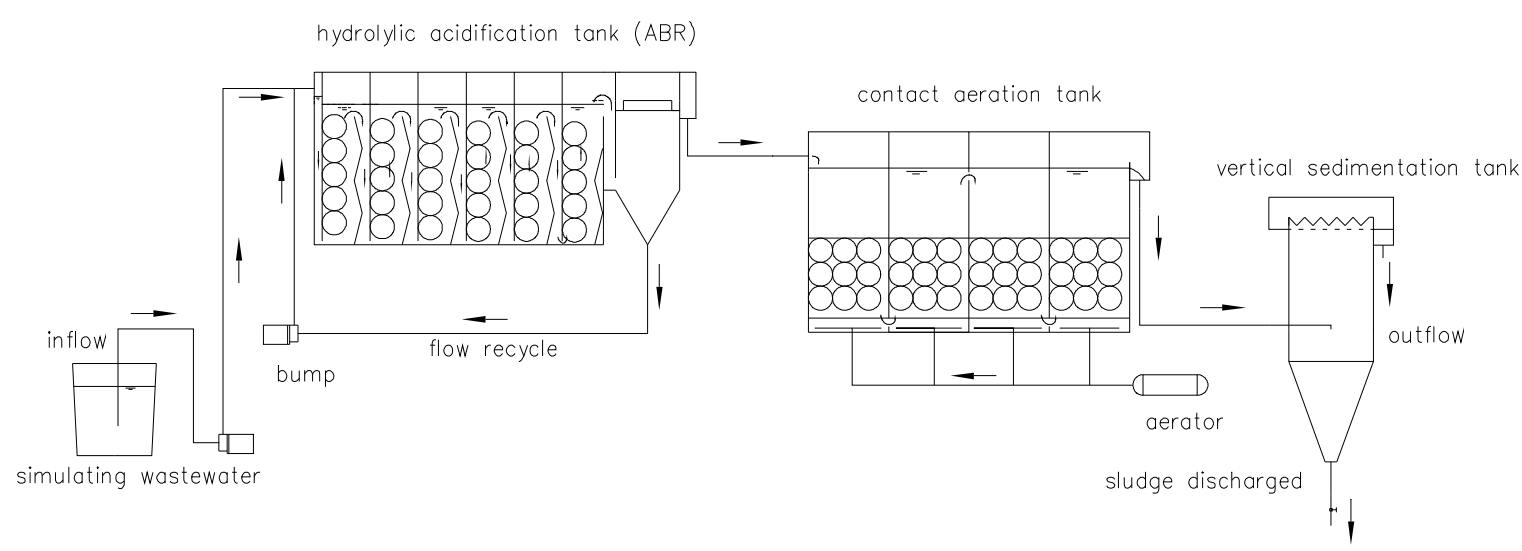

(a) Schematics of processes 1 and 2, classified as group 1 processes.

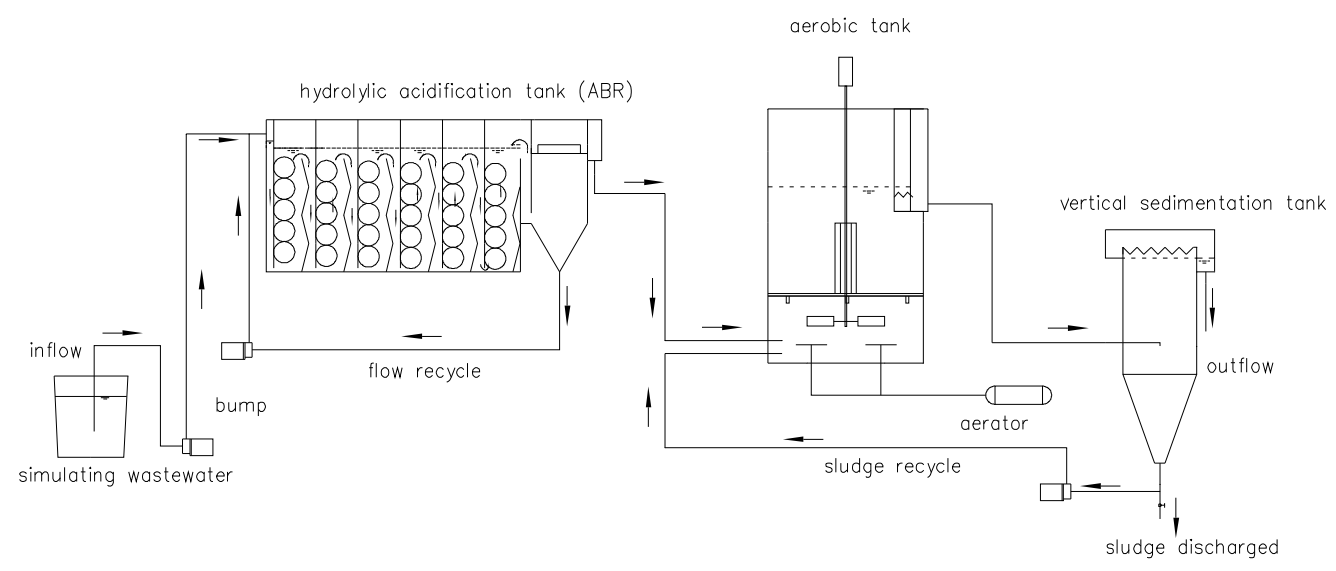

(b) Schematics of processes 3 and 4, classified as group 2 processes.

Fig.1: Schematics of the four treatment processes.

The four processes were fed with simulated dyeing wastewater. Its average COD was in the range of 600-700 $\mathrm{mg} / \mathrm{L}$, which was mainly attributed to sucrose and dyes. The dyes included sulfur black $(0.13 \mathrm{~g} / \mathrm{L})$ and indigo $(0.032 \mathrm{~g} / \mathrm{L})$. Sodium bicarbonate $\left(\mathrm{NaHCO}_{3}\right.$; around $\left.0.08 \mathrm{~g} / \mathrm{L}\right)$, sodium sulfide $\left(\mathrm{Na}_{2} \mathrm{~S}\right.$; around $\left.0.13 \mathrm{~g} / \mathrm{L}\right)$, and sodium hyposulfite $\left(\mathrm{Na}_{2} \mathrm{~S}_{2} \mathrm{O}_{4}\right.$; around $\left.0.038 \mathrm{~g} / \mathrm{L}\right)$ were also added to simulate the dyeing wastewater. Sodium hydroxide $(\mathrm{NaOH})$ was added to keep the $\mathrm{pH}$ of wastewater within the range of 9-11. nonylphenol 10-ethoxylate (NP10EO) of technical grade (named TX-10 in market) were used in the wastewater as target pollutants with concentration of around 12.5-6.25 mg/L. All the chemicals above except sucrose, dyes and TX-10 were of analytical grade and purchased from Yongda (Tianjin, China)

Extraction and analysis. Methods to extract and analyze NPEOs and their biodegradation products have previously been reported in a number of research articles [13-15]. Based upon the literature [9-11], suitable extraction and detection procedures were used for the experiments. These procedures have been outlined in section 2.1.2 and 2.1.3.

Sample preparation. Before filtration, formaldehyde (1:100 in volumes of samples) and sulphuric acid (to adjust the $\mathrm{pH}$ to around 3) were added to the samples for the preservation in the refrigerator. The filter was a kind of glass fiber and was prepared in Muffle Furnace at $450{ }^{\circ} \mathrm{C}$ for $4 \mathrm{~h}$. An Hydrophilic-Lipophilic Balanced (HLB) cartridge was conditioned sequentially with $5 \mathrm{~mL} \mathrm{CH}_{2} \mathrm{Cl}_{2}$, 
$5 \mathrm{~mL} \mathrm{CH}{ }_{3} \mathrm{OH}$, and $5 \mathrm{~mL}$ water. The filtered water (having a $\mathrm{pH}$ of 3 ) was passed through the HLB cartridges at a flow rate of around $5-10 \mathrm{~mL} / \mathrm{min}$. The residual water was removed by passing a gentle nitrogen stream through the cartridges for about $30 \mathrm{~min}$. A total of $10 \mathrm{ml}$ of mixture containing $\mathrm{CH}_{2} \mathrm{Cl}_{2}$ and $\mathrm{CH}_{3} \mathrm{OH}$ in 80:20 volumetric ratio respectively was used as eluent. The eluent was passed through the sorbent beds at a flow rate of $2 \mathrm{~mL} / \mathrm{min}$ to desorb NPEOs. Then, the eluent was dried under a gentle nitrogen stream and regenerated using $1 \mathrm{~mL}$ hexane.

Detection method. The detection methods used for the three kinds of nonylphenol compounds were related to total amounts of NPEO, NP, low-molecular weight NPEOs (nonylphenol monoethoxylate (NP1EO), NP2EO and NP3EO (nonylphenol triethoxylate)), and low-molecular weight NPECs (NP1EC, nonylphenol ethoxy carboxylate(NP2EC) and nonylphenol diethoxy carboxylate(NP3EC)). The detection of total NPEO is based on the methods of Lu and Goel et al $[16,17]$. A liquid chromatograph having a UV detector was used in the experiments. A reversed phase column (ZORBAX Eclipse XDB C-18, Agilent, USA) was used to quantify the amounts of total NPEO. The mobile phase was methanol and water. The detection wavelength was $225 \mathrm{~nm}$ and the column temperature was $30^{\circ} \mathrm{C}$. The flow rate was $1.0 \mathrm{~mL} / \mathrm{min}$, and the injection volume was 10 $\mu \mathrm{L}$. The elution gradient of mobile phase changed from 80:20 (methanol:water respectively) to $85: 15$ in the first $3 \mathrm{~min}$. It remained constant at 85:15 for $7 \mathrm{~min}$, and then changed back to 80:20 in 3 min.

The method for NP and low-molecular weight NPEOs (NP1EO, NP2EO and NP3EO) is similar to that reported by Lian et al [14]. A $7890 \mathrm{~N}$ gas chromatograph (Agilent, Santa Clara, CA) connected to an HP 5975 MSD mass spectrometer (Agilent, Santa Clara, CA) was used for these experiments. Bis(trimethylsilyl)trifluoroacetamide (BSTFA) and chlorotrimethylsilane (TMCS) were used as derivative reagents. A $30 \mathrm{~m}$ DB-5 capillary column $(0.32 \mathrm{~mm}$, inner diameter; $0.25 \mu \mathrm{m}$ thickness) was installed in the GC. The carrier gas was helium and was maintained at a constant flow rate of $0.9 \mathrm{~mL} / \mathrm{min}$. A sample volume of $1 \mu \mathrm{L}$ was injected in splitless mode at an inlet temperature of $300{ }^{\circ} \mathrm{C}$. The column temperature was set to $50{ }^{\circ} \mathrm{C}$ for $1 \mathrm{~min}$ and then changed from $50{ }^{\circ} \mathrm{C}$ to $200{ }^{\circ} \mathrm{C}$ at a rate of $20{ }^{\circ} \mathrm{C} / \mathrm{min}$. After keeping the temperature at $200{ }^{\circ} \mathrm{C}$ for $2 \mathrm{~min}$, it was increased from $200{ }^{\circ} \mathrm{C}$ to $235^{\circ} \mathrm{C}$ at a rate of $5{ }^{\circ} \mathrm{C} / \mathrm{min}$. It was kept at $235^{\circ} \mathrm{C}$ for $5 \mathrm{~min}$ and then was increased from $235{ }^{\circ} \mathrm{C}$ to $280{ }^{\circ} \mathrm{C}$ at a rate of $25^{\circ} \mathrm{C} / \mathrm{min}$. It was then maintained at $280{ }^{\circ} \mathrm{C}$ for $5 \mathrm{~min}$. Quantitative analysis was carried out using selected ion monitoring (SIM) mode. For each compound, the most abundant ions were selected from its spectrum. The chosen ions for SIM were: 179 for 4-n-NP; 221, 179 and 193 for NP; 251 and 265 for NP1EO; 295 and 309 for NP2EO; and 281 and 267 for NP3EO.

The detection of low-molecular weight NPECs (NP1EC, NP2EC and NP3EC) is based on the method of Ding and Lu [15, 18]. Same GC-MS and capillary column were used for NPEOs (NP1EO, NP2EO and NP3EO). n-propanol and acetyl chloride were used as derivative reagents. The carrier gas was helium and was maintained at a constant flow rate of $2.6 \mathrm{~mL} / \mathrm{min}$. A sample volume of $1 \mu \mathrm{L}$ was injected in splitless mode at an inlet temperature of $275{ }^{\circ} \mathrm{C}$. The column temperature was set to $130{ }^{\circ} \mathrm{C}$ for $5 \mathrm{~min}$ and then increased to $280{ }^{\circ} \mathrm{C}$ at a rate of $5{ }^{\circ} \mathrm{C} / \mathrm{min}$. It was then maintained at $280{ }^{\circ} \mathrm{C}$ for $20 \mathrm{~min}$. Quantitative analysis was carried out using selected ion monitoring (SIM) mode. For each compound, the most abundant ions were selected from the spectrum. The chosen ions were: 221, 235, 249, 263 and 277 for NP1EC; 103 and 145 for NP2EC; 103 and 145 for NP3EC.

The suitability of three chosen methods was tested by applying these on clean water containing TX-10 and the simulated wastewater. Recoveries for NP, low-molecular weight NPEOs and 
low-molecular weight NPECs were found to be $77 \%, 86 \%$, and $74 \%$ respectively.

Materials and instruments. $\mathrm{NaOH}, \mathrm{NaHCO}_{3}$ and $\mathrm{Na}_{2} \mathrm{~S}_{2} \mathrm{O}_{4}$ used in simulated wastewater were of analytical grade and purchased from Yongda (Tianjin, China). TX-10 (NP10EO in technical grade) was purchased from Xiaowei Chemical Co., Ltd. (Guangzhou, China). The average molecular number of ethyleneoxide (EO) unit was around 10. Chemicals such as dichloromethane (DCM) and n-propanol, which were used in the analysis, were of chromatographic grade. The standards of NP, low-molecular NPEOs (NP1EO, NP2EO and NP3EO), low molecular NPECs (NP1EC, NP2EC and NP3EC), and 4-n-NPEO were purchased from Dr. Ehrenstorfer GmbH, Germany. The volume and weight of HLB cartridge column were $6 \mathrm{~mL}$ and $500 \mathrm{mg}$ respectively, and was purchased from Waters Co. (Milford, MA,USA). The glass fiber filter was of $0.7 \mu \mathrm{m}$ (Grade GF/F, Whatman) and was purchased from international GE Healthcare, USA.GC-MS (model: 6890N/5975B) was purchased from Agilent Co., USA (Santa Clara, CA, USA). The purity of carrier gas (Helium) was more than $99.99 \%$. The reaction gas in NCI mode was methane and also had a purity of more than 99.99\%.Agilent 1220 HPLC and Agilent Poroshell 120 EC-C18 (2.7 $\mu \mathrm{m}, 4.6 \times 50 \mu \mathrm{mm})$ chromatographic column was used to detect the total NPEOs. A pH meter (pHS-3D, Shanghai Rex Instrument Factory, China) was used to determine the $\mathrm{pH}$ of the wastewater.

Experimental procedure. The experiments were conducted under different conditions and five time-based stages were observed for each experiment. The operational parameters of the processes changed with the change in the stage. In stage 1 , a constant flow pump was used to maintain the flow rate a constant value of $100 \mathrm{~L} / \mathrm{min}$. Hydraulic retention times (HRT) for acid hydrolysis, contact aeration and aeration unit were found to be $9.6 \mathrm{~h}, 10.7 \mathrm{~h}$, and $12.8 \mathrm{~h}$, respectively. The recycling rate of hydrolysis units of group 1 (processes 1 and 2) was $100 \%$ and that of group 2 was $50 \%$. In stage 2, the experimental parameters of four processes were the same as those in stage 1 except that the flow rates were maintained at 106, 74, 120 and $70 \mathrm{~L} / \mathrm{d}$. Due to this change, the HRT also changed (see Table 1). In stage 3, all operational parameters had same values as those in stage 2 except that the recycling rate of acid hydrolysis units were changed from $100 \%$ to $50 \%$ (for group 1) and from $50 \%$ to $100 \%$ (for group 2). In stage 4, the operational parameters had same values as those in stage 3 except the composition of the simulated wastewater. The amount of dye used in stage 4 was $20 \%$ more than that which was used in the first three stages. Additionally, the amount of TX-10 was also reduced by $50 \%$ than the amount used in the first three stages. In stage 5 , the operational parameters and composition of wastewater were kept as that in stage 4 except that the flow rates of the four processes were changed back to $100 \mathrm{~L} / \mathrm{d}$.

Table 1: HRT of treatment units under different flow conditions.

\begin{tabular}{|c|c|c|c|c|}
\hline $\begin{array}{ll}\text { flow } & \text { rate } \\
\text { (liter/day) } & \end{array}$ & $\begin{array}{l}\text { anaerobic } \\
\text { hydrolysis unit } \\
\text { (hour) }\end{array}$ & $\begin{array}{l}\text { aerobic contact } \\
\text { unit (hour) }\end{array}$ & $\begin{array}{l}\text { conventional } \\
\text { aerobic unit } \\
\text { (hour) }\end{array}$ & $\begin{array}{l}\text { vertical } \\
\text { sediment unit } \\
\text { (hour) }\end{array}$ \\
\hline 100 & 9.6 & 10.7 & 12.8 & 3.8 \\
\hline 106 & 9.1 & 10.1 & 12.0 & 3.6 \\
\hline 74 & 13.0 & 14.5 & 17.2 & 5.2 \\
\hline 120 & 8.0 & 8.9 & 10.6 & 3.2 \\
\hline 70 & 13.7 & 15.3 & 18.2 & 5.5 \\
\hline 110 & 8.7 & 9.7 & 11.6 & 3.5 \\
\hline
\end{tabular}




\section{Results and discussion}

COD removal efficiency. Fig. 2 shows the efficiencies of the two treatment groups on the removal of COD. The effluent CODs from all processes were under $100 \mathrm{mg} / \mathrm{L}$ and after four treatment processes, reached the effluent standard set for dyeing wastewater of China. An overall removal rate of more than $85 \%$ was achieved by the studied processes. On average, the influent concentration of COD was reduced by $33 \%$ in the anaerobic tanks, while the $\mathrm{pH}$ decreased from 11.0 to 9.0. The results show that the efficiency of the anaerobic units has not been impacted by the strong alkalinity of wastewater.

In aerobic unit, a higher removal efficiency of COD is observed (see Fig. 2). On average, the two aerobic tanks from group 1 achieved a removal rate of $92 \%$ and those from group 2 achieved a corresponding value of $88 \%$. After pretreatment in anaerobic unit, the biomass present in aerobic unit shows its ability to biodegrade the organic matter present in the simulated dyeing wastewater. The residue dyes and the alkali show no impact on aerobic treatment.
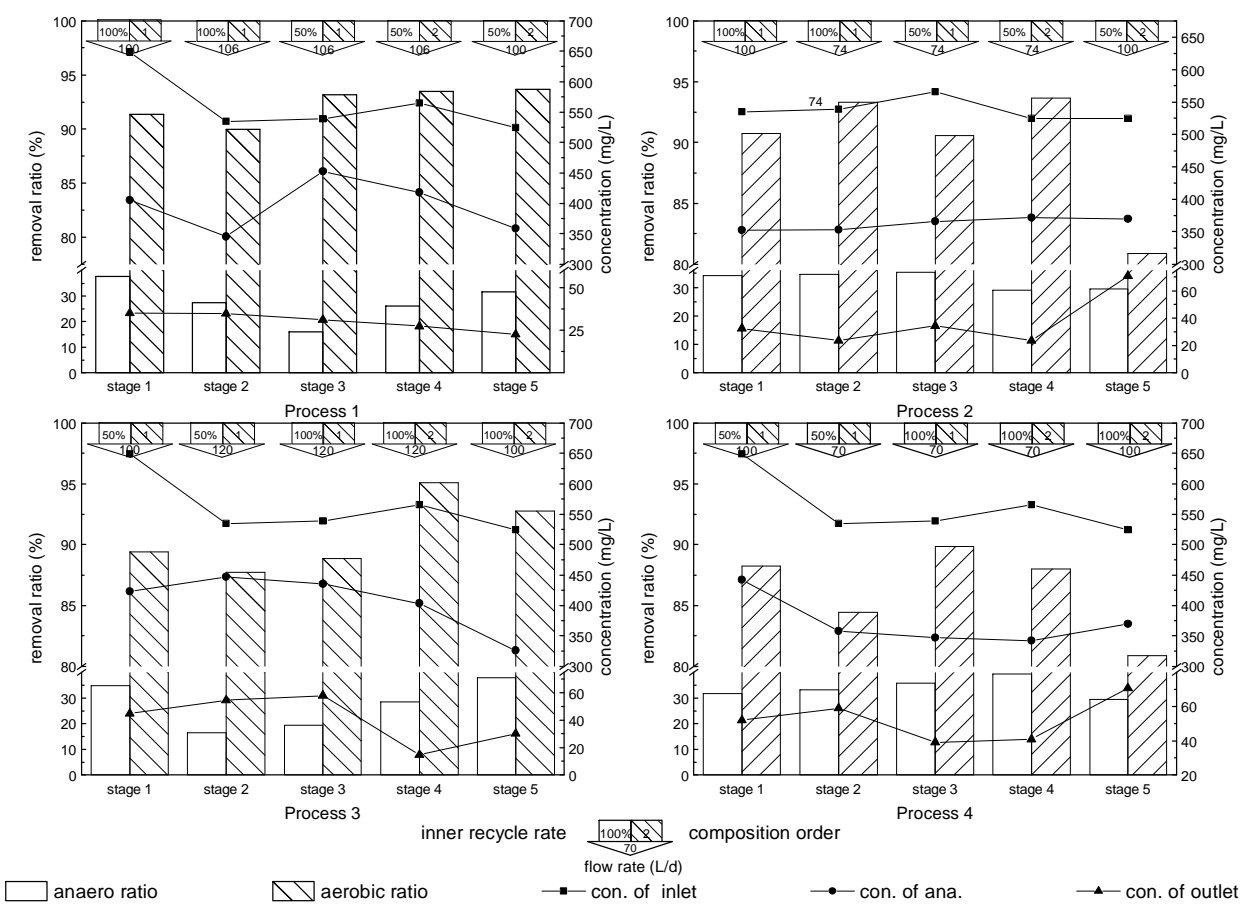

Fig.2: removal rate and concentration of COD from anaerobic and aerobic units of four treatment processes

It is also observed in Fig. 2 that the two processes from group 1, accompanied by aerobic contact tanks, achieved a more effective COD removal rate than those from group 2 (with the value of $94 \%$ and $88 \%$ respectively). The former got an average effluent concentration under $50 \mathrm{mg} / \mathrm{L}$. On average, the COD concentration from group 2 was higher than that from group 1 and ranged between 40-90 $\mathrm{mg} / \mathrm{L}$. The tiny sludge particles suspended in the effluent are thought to be responsible for the above mentioned discrepancy. Many tiny and light sludge particles were observed in the outlet from the conventional aerobic unit of group 2. Due to small size, it was easier for the particles to escape the sediment tanks and thus, resulted in an elevation of COD value.

Removal of NPEOs in anaerobic and aerobic tanks. The results for the average removal rates of total NPEOs are shown in Fig. 3. Low concentration and high removal rate of NPEOs of the four processes indicate that a high $\mathrm{pH}$ value of the influent does not have any influence on the removal of NPEOs. Meanwhile, it is observed that the average removal rates from two groups had the same value of $94 \%$, though the rates of COD from the two groups did not have the same value. As 
deducted in section 3.1, the difference in COD values might have occurred due to the presence of tiny active sludge suspended in the effluent. Therefore, the biodegradation products of NPEOs were thought to have a weak hydrophobicity. This is due to the reason that if the products had a strong hydrophobicity, much of them would be adsorbed onto the sludge and would result in discrepancy in the removal rates of NPEOs for both the groups. On the contrary, both the groups have shown same value for the COD ratios, which is $94 \%$.

The results also show that the anaerobic unit reduced the influent concentration of total NPEOs by around $38 \%$, which is slightly higher than its contribution in case of the COD removal. The removal rate of total NPEO achieved in the aerobic unit was more than $92 \%$, which confirmed the high removal rate achieved by the process. These results highlight the high removal efficiency for NPEOs despite strongly basic conditions in the dyeing wastewater treatment processes.
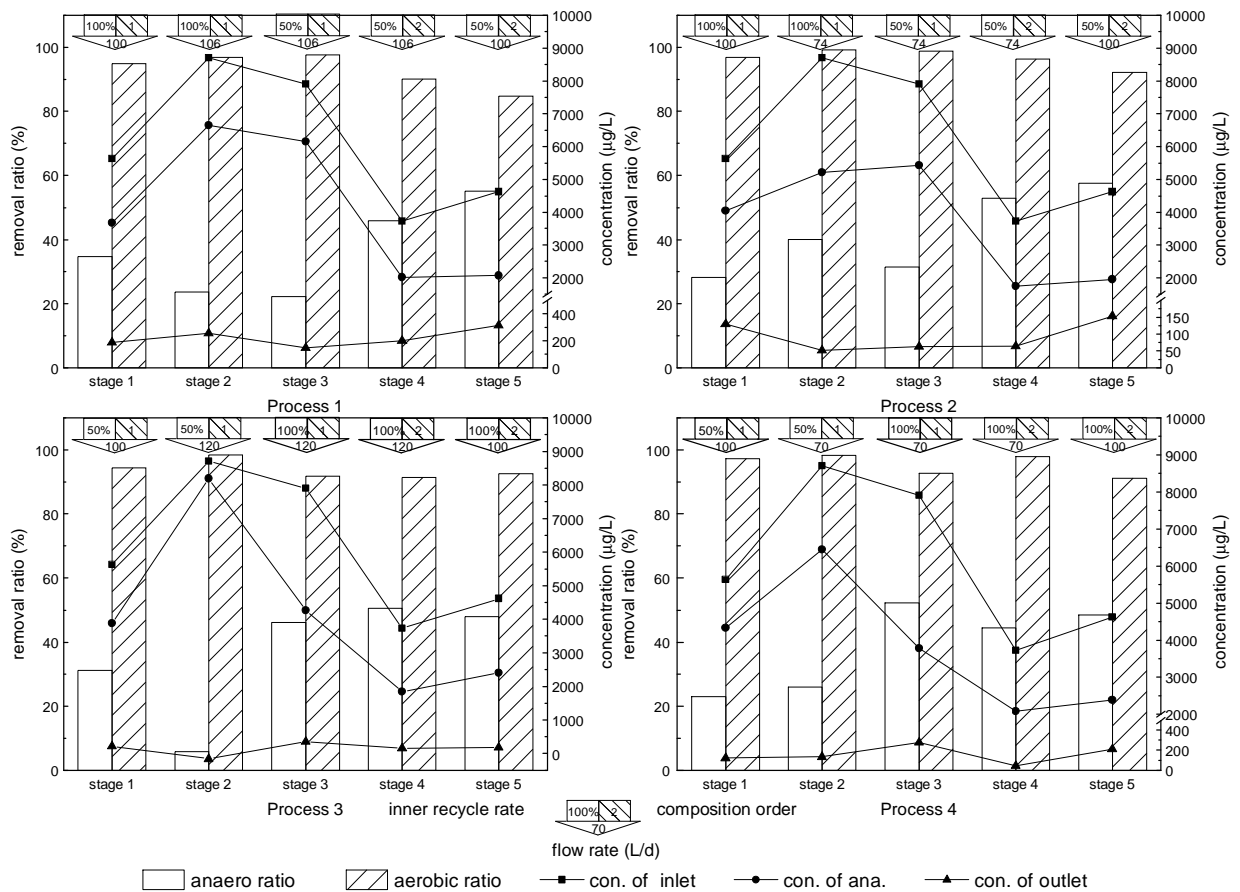

Fig.3: removal rate and concentration of total NPEO from anaerobic and aerobic units of four treatment processes

Removal of NP and NPEOs (NP1EO, NP2EO and NP3EO). The concentration variations of NP and low molecular NPEOs (NP1EO, NP2EO and NP3EO) are illustrated in Fig. 4. The total concentration of these species initially increased from around $1000-1500 \mu \mathrm{g} / \mathrm{L}$ to $2000-8000 \mu \mathrm{g} / \mathrm{L}$ after the treatment in the hydrolysis anaerobic unit and then dropped to around $500-3000 \mu \mathrm{g} / \mathrm{L}$ when flowing out of the aerobic unit. The increase in anaerobic unit is in accordance with the similar results reported in literature, stating that higher molecular weight NPEOs get converted to low molecular NPEOs under anaerobic conditions [19-21]. But the increase in amounts of low molecular weight NPEOs under anaerobic conditions was not enough to make up the total decrease in NPEOs. Considering the possible degradation products and their physico-chemical properties, the missing degradation products are supposed to be either adsorbed to the sludge or converted to chemicals which do not belong to NPEOs and therefore, had escaped being detected in the outlet. Additionally, the results show that the concentrations of NP and low molecular weight NPEOs were decreased by around $60 \%$ in the aerobic unit. Substantial amounts of NP and low molecular weight NPEOs were detected in the effluent from last settling tanks, which present a pollution risk by NP and low molecular weight NPEOs. 
Concentration of low molecular weight NPECs in the treating processes.The concentration variation of low molecular weight NPECs is illustrated in Fig. 5. The results of low concentration (ca. 30-50 $\mu \mathrm{g} / \mathrm{L}$ ) in the anaerobic unit back the theory that the low molecular weight NPECs are not the intermediate biodegradation products of NPEOs under anaerobic conditions [15, 22, 23]. Additionally, the effluent concentration of NPECs (NP1EC, NP2EC and NP3EC) was increased to $1300 \mu \mathrm{g} / \mathrm{L}$ in the aerobic tanks, which is in accordance with the previous studies proving that the NPECs were the products of NPEOs under aerobic conditions [24, 25].
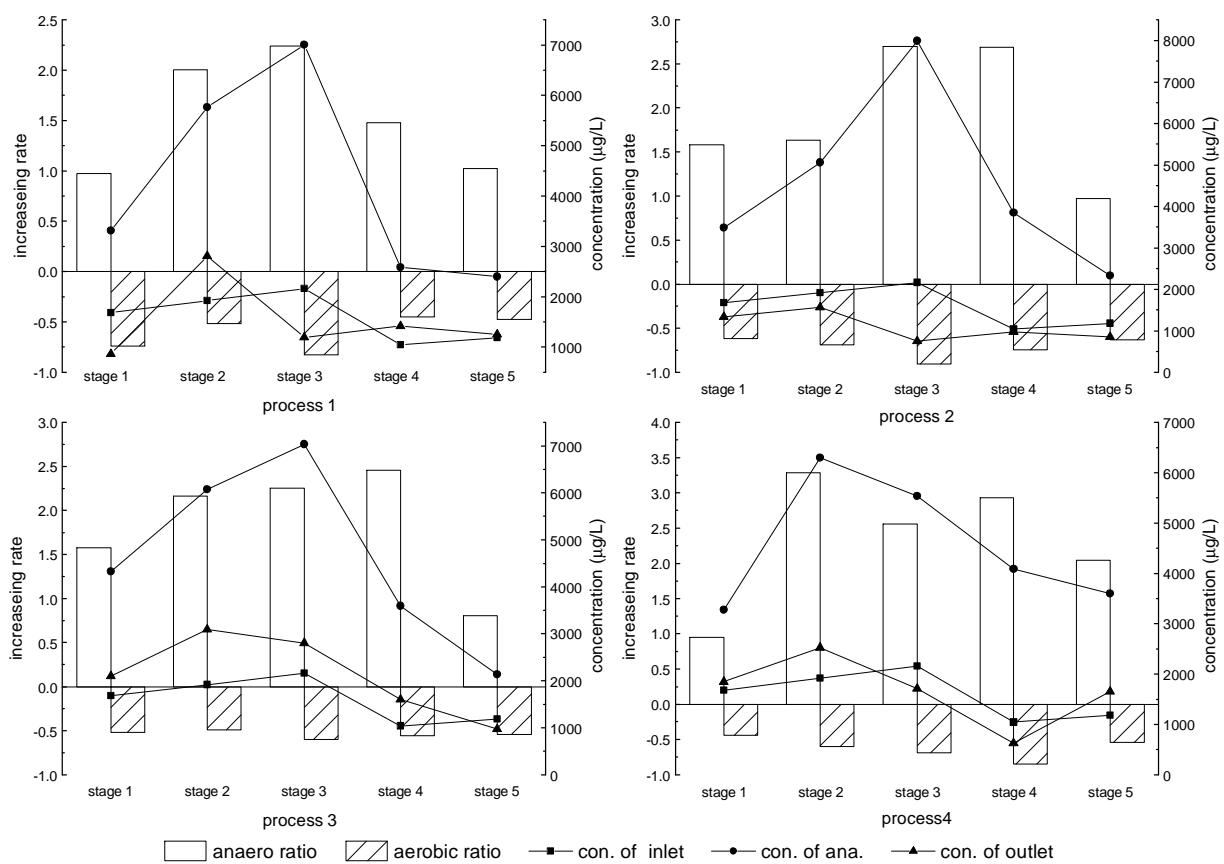

Fig.4: increase rate and concentration of NP etc. from anaerobic and aerobic units of four treatment processes
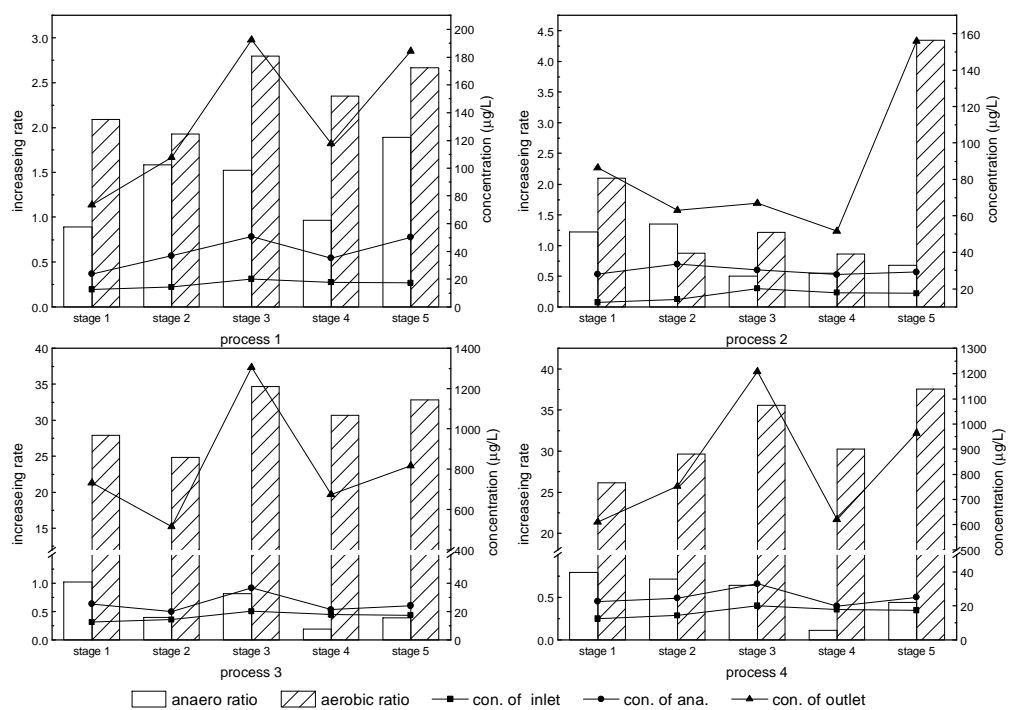

Fig.5: increase rate and concentration of low molecular weight NPEC from anaerobic and aerobic units of four treatment processes

The results also show that there is a distinct difference in the concentrations of NPECs of both the processes. Group 1, accompanied by contact aerobic tanks, achieved a concentration of around 
50-190 $\mu \mathrm{g} / \mathrm{L}$, while the group accompanied by conventional sludge aerobic tanks achieved a concentration of around 500-1330 $\mu \mathrm{g} / \mathrm{L}$. Although the concentrations of these species increased significantly in both aerobic groups, the outlet concentration from group 2, connected with conventional active sludge, was 8-15 times higher than that from group 1 and was also 17-40 times higher than the inlet concentration. The results suggest that a more favorable environment was presented in the conventional active sludge system, which favored the production of low molecular weight NPECs. As the biodegradation theory of NPEO suggests, the NPECs are the products of oxidation of NPEOs. The contact of oxygen and sludge in the reaction unit would inevitably influence the oxidation of NPEOs. Therefore, a more hostile environment in case of group 2 would prompt a higher production of NPECs from NPEOs. On the contrary, the neutral environment in the contact aerobic units in case of group 1 would limit the contact of oxygen and NPEOs, especially those NPEOs which were absorbed in the sludge, and consequently, influenced the NPEO production. The results show that the contact between the sludge and oxygen is an important factor for the production of NPECs. It was reasonable to believe that the NPEOs, with a relatively high solubility and which approached oxygen more easily, can achieve high rate of conversion to NPECs. Due to a poorer approach, the hydrophobic low molecular weight NPEOs will achieve a lower conversion rate.

Biodegradation pathway of NPEOs during the dyeing wastewater treatment. Based upon the achieved results, a biodegradation pathway for the NPEOs in dyeing wastewater has been proposed.

In the first and the anaerobic hydrolysis unit, the NPEOs in the influent were reduced by around $30 \%$ in terms of concentration. These reduced had either been mineralized or were converted to lower molecular weight NPEOs which were partly adsorbed by the activated sludge. The NPEOs left were mostly hydrophilic and had relatively higher molecular weight. As described previously by some researchers [26, 27], the low molecular weight NPECs were not the products of the anaerobic unit. The increase in low molecular weight NPEOs was the result of biodegradation of high molecular weight NPEOs and is in agreement with the biodegradation theory of the NPEOs under anaerobic conditions $[15,28]$. Furthermore the amount of low molecular weight NPEOs produced was lower than that of NPEOs removed in the anaerobic units. The result indicates that not all NPEOs reduced were converted to low molecular weight NPEOs in the water, some of them might be transformed to other products and be mineralized, some might be converted to NP, NP1 3EO but adsorbed to the sludge. Apart from the NP, and NP1 3EO detected in water, NPEOs detected were mostly high molecular weight NPEOs with hydrophilic characteristics.

The outlet of the anaerobic unit contained both low and high molecular weight NPEOs. When entering into the aerobic unit, some low molecular weight NPEOs might be absorbed by activated sludge. But most NPEOs would be degraded and a total elimination rate of around $90 \%$ will be achieved. Considering the results deduced in section 3.2 (the biodegradation products may be hydrophilic), we conclude that the NPEOs in aerobic unit are mostly either converted to hydrophilic compounds or be mineralized. The hydrophilic nonylphenol compounds like NPECs, CNPEOs and CNPECs are all suspected to be produced by NPEOs. These results are also supported by the reasoning based upon the elimination of low molecular weight NPEOs. In our experiments, the concentration of low molecular weight NPEOs for the two groups showed a sharp decline after being treated in the aerobic units (on average around 60\%). The value was far below the value representing the decrease in total NPEOs (on average around 90\%). It meant that the elimination rate of low molecular weight NPEOs was lower than that of total NPEOs (including low and high molecular weight molecules). There exist three theories describing the production of low molecular weight NPEOs in the past few years. According to the first theory, low molecular weight NPEOs are 
the intermediate products of high molecular weight NPEOs and are produced under aerobic conditions. The $\mathrm{NP}(\mathrm{n}) \mathrm{EO}$ are firstly transformed to $\mathrm{NP}(\mathrm{n}) \mathrm{EC}$, which are then converted to $\mathrm{NP}(\mathrm{n}-1) \mathrm{EO}$ with the loss of an EO group [29]. The loss of EO will continue unless it is intercepted by another biodegradation pathway. Therefore, the low molecular weight NPEOs may accumulate progressively if there are no favorable conditions for the oxidation or mineralization of these species. The second theory suggests that the EO unit will be removed without the production of corresponding NPECs in anaerobic unit [30]. The third theory states that the breakage of EO chain would take place in the middle of the molecule, which results in the production of low molecular weight NPEOs [31]. The detection of substantial low molecular weight NPECs in the effluent indicates that the results are in a better accordance with the first theory than the other two. The second and third theories cannot deduce the production of NPECs. Therefore, based on the high removal rate of total NPEOs achieved in our experiments, it can be suggested that the high molecular weight NPEOs are rapidly transformed in aerobic unit and result in products not belonging to NPEOs. Otherwise, there would not be high removal rate of total NPEOs. Additionally, low molecular weight NPEOs would be transformed to corresponding NPECs according to the theory. But the relatively low removal rate of low molecular weight NPEOs indicates that it is either more difficult for these species to be transformed or there is a different route to create new low molecular NPEOs in aerobic unit which somewhat offsets the decreasing trend. Considering the high removal rate of total NPEOs, which indicates no substantial NPEOs was detected in the final outlet, it is suggested the NP and low molecular weight NPEOs detected in the outflow would be those coming from the anaerobic unit and the transformation of NP and NP1 3EO is a relative difficult process in the aerobic unit. To control the effluent concentration of low molecular weight NPEOs, fewer NPEO products should be considered in anaerobic unit.

The concentration difference of low molecular weight NPECs existing between the two groups for the aerobic outlet confirms the fate of low molecular weight NPEOs. As mentioned in section 3.4 , the two groups do not have the same value for the outlet concentration of low molecular weight NPECs. It is suggested that the more intense agitation presented in the conventional active sludge system prompt the contact between the sludge and oxygen and result in more production of NP1 3EC from NP1 3EO.

Additionally, the results show that the amounts of low molecular weight NPECs produced in the aerobic unit (ranging from $98 \mu \mathrm{g} / \mathrm{L}$ to $850 \mu \mathrm{g} / \mathrm{L}$ ) were far lower than the amounts of low molecular weight NPEOs eliminated in the same unit (ranging from $1600 \mu \mathrm{g} / \mathrm{L}$ to $4000 \mu \mathrm{g} / \mathrm{L}$ ). It indicates that the low molecular weight NPEOs, which got converted to NPECs, constituted a small part of the total NPEOs, especially that from the group 1. So there might be other biodegradation intermediates not belonging to low molecular weight NPECs during the treatment process. In case of other relevant products such as CNPEO, CNPEC are the biodegrade products of NPEOs. The mineralization and the breaking of phenyl ring could also be the pathway of the biodegradation. It is a pity that no clear pathway can be concluded due to the limitation of detection mechanisms for all the products listed above.

\section{Influence of operating parameters.}

Inner recycle of anaerobic unit. An inner recycle of flow was applied in the anaerobic unit to improve contact between biomass and pollutants. The recycle rates of 50\% and $100 \%$ were applied in the two groups during different stages. In group 1, the rate of 50\% was applied in the first two stages and a rate of $100 \%$ was used in the next three stages. A converse order was applied in the group 2: the first two stages used a recycle rate of $100 \%$, while the last three had a recycle rate of $50 \%$. For the parameters studied in current research, when the recycle rate was increased from 50\% 
to $100 \%$, the inlet concentration decreased by $6 \%$ but the flow rate increased by $30 \%$. Therefore, the promotion of contact between the biomass and pollutants resulted from the increase of flow rate and was mainly influenced by the inner recycle. The corresponding results of the experiment have been illustrated in Fig. 2 and Fig. 3. Figure 2 shows that the elimination rate of COD was elevated with the increase of recycle rate (see Fig. 2 when switch stage 2 to stage 3). The removal rate of total NPEO was increased too with the increase of recycle rate (see Fig. 3 when switch stage 2 to stage 3). However a gap was observed between the variation ranges in the removal rate from four processes. In case of COD and NPEOs the ranges were around $6 \%$ and $20 \%$ respectively. It indicates that the removal rate of NPEOs is more easily affected by the switch of recycle rate than the rate of COD. The COD of the inlet was mainly composed of easily biodegradable chemical, namely, sucrose. When the reaction time in the anaerobic unit is long enough, the removal rate of biodegradable chemical will slow down, which resulted in a more small variation range. The results about elimination of COD from our study are in accordance with the biodegrading characteristics of sucrose. Therefore, the more large variation range of the NPEOs confirms the relative difficulty for anaerobic biodegradation of NPEO. A more violent stirring would prompt the biodegradation. It means that the promotion of contact between the biomass and pollutants (resulting from the increase of inner recycle rate) would prompt the elimination of high molecular weight NPEOs.

In case of the production of low molecular weight NPEOs, the results show that in the anaerobic unit there were three decreases in production rate with the increase of recycle rate for all four processes studied. There would be other factors which affected the production of low molecular weight NPEOs in anaerobic tank. The discussion of these factors is beyond the scope of current study and therefore, has not been included in this work.

Influence of composition of dyeing wastewater. When processing denim, dyeing additives (NPEOs) are used to absorb the hydrophobic dye particles and help their dispersion in the dyeing water. Therefore, the amount of dyes will influence the appearance of the NPEOs in the water, which in turn affects their biodegradation in the wastewater. To investigate the influence of the dyes, simulated wastewater of two different compositions was used in the studied processes. One kind of the simulated wastewater was used in the first three stages of the experiment, while the other was applied to the last two stages. Compared with the former, the latter wastewater increased the dyes by about $20 \%$ while reducing the NPEOs by about 50\%. These results are illustrated in Fig. 2 and Fig. 3. Fig. 2 shows that the removal efficiency of COD in the anaerobic tank increased when the dyes were increased in studied processes (from stage 3 to stage 4). The variation in removal rate was attributed to the HRT of the unit. When the HRT changed from 8 hour to 13 hour (different HRT for four processes), the corresponding change in variation was from $10 \%$ to $3 \%$. A similar increasing trend was found for the removal of total NPEOs from process 1, process 2, and process 3. But a decreasing trend (from 52\% to 44\%) was observed in process 4 when the dyes were increased. These results indicate that the amount of dyes affect the removal of NPEOs more greatly than the COD. It also shows that when the amounts of dye are changed, the corresponding degradation of NPEOs in the anaerobic unit is significantly affected.

\section{Conclusion}

The results obtained from the current study show that the acrid environment and the presence of dyes in wastewater do not pose any hindrance to the degradation of nonylphenol compounds in the dyeing wastewater. A high removal rate of NPEOs accompanied by high elimination of COD can be observed in the dyeing wastewater treatment. The removal rates of NPEOs detected in anaerobic hydrolysis and aerobic unit achieve values of $30 \%$ and $90 \%$ respectively, which subsequently result 
in a high removal rate of NPEOs. A relatively higher concentration of low molecular weight NPEOs in the aerobic unit partly result from the high inlet concentration inherited from anaerobic unit and the relatively low removal efficiency in the aerobic tanks. The processes along with contact oxidation will yield lesser low molecular weight NPECs than the conventional aerobic sludge system. The intense agitation in the conventional activated sludge units promote the contact between the NPEOs, oxygen and biomass and thus, results in a higher production of NPECs. Based upon the elimination rate differences between the NPEOs and COD, it is suggested that NPEOs have been converted to hydrophilic chemicals except those mineralized. The low molecular weight NPECs are not the main biodegraded products in the aerobic unit. A favorable environment is required for the production of NPECs. The amounts of low molecular weight NPEOs remained in the effluent and are affected by the residual NPEOs inherited from the anaerobic units. To control the NPEOs discharged to the natural waters, the anaerobic unit should be improved to cut down the amounts of low molecular weight NPEOs produced. A contact oxidation unit is also proposed due to its contribution towards a more efficient elimination of the NPEOs and less production of NPECs.

\section{Acknowledgements}

This work was financially supported by the Water Pollution Control and Treatment Special Project of China (2012ZX07206-003)

\section{References}

[1] ICIS, Overview of the U.S. Nonylphenol Sector,Focus on Surfactants. 2007.

[2] Soares, A., et al., Environment International, vol 34(7) (2008). p. 1033.

[3] Renner, R., Environmental science \& technology, vol 31(7) (1997). p. 316A.

[4] The ecnomic anylysis of chinese petrol and chemical industry vol (04) (2012). p. 48.

[5] Cui, X., Digest of chemical industry, vol (10) (2002). p. 49.

[6] Jobling, S., H.S. A, and J.P. Sumpter, Endocrinology, vol 135(1) (1994). p. 175.

[7] C, M.G. and K. U, Endorcine, vol 102(5) (1978). p. 1429.

[8] Soto, A.M., H. Justicia, and J.W. Wray, Environmental Health Perspectives, vol 92 (1991). p. 167.

[9] Li, X., et al., Environ Int, vol 36(6) (2010). p. 557.

[10] Zhao, J.-L., et al., Journal of Environmental Monitoring, vol 13(4) (2011). p. 813.

[11] Kumar, V., C. Majumdar, and P. Roy, Journal of Steroid Biochemistry and Molecular Biology, vol 111(3-5) (2008). p. 208.

[12] Karci, A., Chemosphere, vol (0) (2013.

[13] Ding, W.H. and S.H. Tzing, Journal of Chromatography A, vol 824(1) (1998). p. 79.

[14] Lian, J., J.X. Liu, and Y.S. Wei, Science Of The Total Environment, vol 407(14) (2009). p. 4261.

[15] Lu, J., et al., CHEMOSPHERE, vol 71(2) (2008). p. 345.

[16] Lu, J., et al., Chemosphere, vol 69(7) (2007). p. 1047.

[17] Goel, A., et al., Acta Hydrochimica et Hydrobiologica, vol 31(2) (2003). p. 108.

[18] Ding, W.H. and C.T. Chen, Journal of Chromatography A, vol 862(1) (1999). p. 113.

[19] Ahel, M., C. Schaffner, and W. Giger, Water Research, vol 30(1) (1996). p. 37.

[20] Ejlertsson, J., et al., Environmental Science \& Technology, vol 33(2) (1999). p. 301.

[21] Luppi, L.I., et al., Chemosphere, vol 68(11) (2007). p. 2136. 
[22] Chiu, T.Y., et al., vol 40 (2010). p. 199.

[23] Di Corcia, A., et al., Environmental Science \& Technology, vol 34(18) (2000). p. 3914.

[24] Hayashi, S., et al., Environmental Science \& Technology, vol 39(15) (2005). p. 5626.

[25] Omeroglu, S. and F.D. Sanin, Water Research, vol 64 (2014). p. 1.

[26] Field, J.A. and R.L. Reed, Environmental Science \& Technology, vol 33(16) (1999). p. 2782.

[27] Ferguson, P.L. and B.J. Brownawell, Environmental Toxicology and Chemistry, vol 22(6) (2003). p. 1189.

[28] NAYLOR, C.G., et al., Journal Of The American Oil Chemists Society, vol 69(7) (1992). p. 695.

[29] Jonkers, N., T.P. Knepper, and P. De Voogt, Environmental Science \& Technology, vol 35(2) (2001). p. 335.

[30] John, D.M. and G.F. White, Journal of Bacteriology, vol 180(17) (1998). p. 4332

[31] Franska, M., et al., Water Research, vol 37(PII S0043-1354(02)00444-X5) (2003). p. 1005. 